\title{
Validation of a quantitative food-frequency questionnaire for use in Western Mali
}

\author{
Liv E Torheim ${ }^{1, *}$, Ingrid Barikmo ${ }^{1}$, Anne Hatløy ${ }^{2}$, Moro Diakité ${ }^{3}$, Kari Solvoll ${ }^{4}$, \\ Modibo M Diarra ${ }^{5}$ and Arne Oshaug ${ }^{1}$ \\ ${ }^{1}$ Akershus University College, Ringstabekkveien 105, N-1356 Bekkestua, Norway: ${ }^{2}$ Fafo Institute for Applied \\ Social Science, Oslo, Norway: ${ }^{3}$ Aideb, Bafoulabé, Mali: ${ }^{4}$ Institute for Nutrition Research, University of Oslo, \\ Norway: ${ }^{5} \mathrm{CPS}$, Ministère de la Sante, Bamako, Mali
}

Submitted 10 July 2000: Accepted 9 May 2001

\begin{abstract}
Objective: The purpose of this study was to validate a quantitative food-frequency questionnaire (QFFQ) created for assessing the usual intake of foods and nutrients in the prevailing season in Western Mali.

Design: Intake of foods and nutrients over the week preceding the interview was measured with a 69-item QFFQ. Intakes were compared with intakes as measured with 2-day combined weighed and recalled diet records.

Setting: A rural village in Western Mali, West Africa.

Subjects: Twenty-seven men and 48 women (15-59 years of age) representing 18 households.

Results: Spearman rank correlations between intake of food groups from the QFFQ and the diet record ranged from 0.09 (meat/fish) to 0.58 (tea/coffee). Median coefficient was 0.37 . Median Spearman correlation coefficient for nutrient intake was 0.40. Men had higher median correlation coefficients than did women. The proportion of subjects being classified into the same quartile of food intake was on median 33\%, while a median of $7 \%$ was misclassified into extreme quartiles. Correct classification into the same quartile for intake of nutrients was on median $34 \%$ while a median of $4 \%$ was grossly misclassified. Intakes of most food groups and nutrients as measured by the QFFQ were higher than those measured by the diet records. However, while men had higher estimated intakes for foods eaten inbetween meals, women in general had higher intake of foods eaten in the main meals.

Conclusion: This QFFQ can be used for comparing the intake of foods and nutrients between groups within this study population. It therefore represents a useful tool in the surveillance of food intake in the population, both in identifying vulnerable groups and for tracking food intake over time. The differences between men and women in overestimating food intake need to be taken into account when using the method.
\end{abstract}

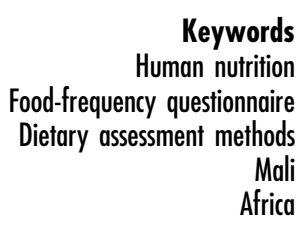

It has been argued that data on dietary intake should be part of nutrition surveillance systems for use in planning policies and strategies, and for monitoring and evaluation purposes ${ }^{1}$. However, in low-income countries, the lack of cost-effective dietary assessment methods makes it difficult to include such data in larger-scale or repeated studies. In these countries the more cumbersome and expensive techniques of weighed records ${ }^{2-4}$ and 24-hour recall $^{5,6}$ have most often been employed. It is therefore necessary to develop quantitative methods for assessing dietary intake in larger population groups in low-income countries. A stronger focus on food-based dietary guidelines, as recommended by the Food and Agriculture Organization of the United Nations/World Health Organization $(\mathrm{FAO} / \mathrm{WHO})^{7,8}$, is another argument for strengthening the efforts in developing dietary assessment methods

The food-frequency questionnaire (FFQ) is currently the method most often used for assessing food intake in larger epidemiological studies in industrialised countries. It represents a simple tool that allows for ranking of individuals ${ }^{9}$; however, its ability to quantify the absolute intake of foods and nutrients is in general limited ${ }^{10}$. To our knowledge, use of this method in low-income 
countries has only recently been reported, by Hebert and co-workers in India ${ }^{11,12}$ and Sharma and co-workers in Cameroon and Jamaica ${ }^{13}$.

Low day-to-day intra-individual variation and relatively few food items available ${ }^{2,14}$ may render the FFQ method especially appropriate for use with African populations. On the other hand, high levels of illiteracy and the eating from common plates, which is practised in many population groups, might make use of the FFQ approach more complicated.

An FFQ has to be developed and validated specifically for each region in order to be culturally sensitive and to correspond to the prevailing food culture ${ }^{15}$. While several versions of FFQs have been validated in industrialised countries $^{9,16-18}$, no publication on validation of an FFQ for use in Africa was found when searching Medline and Popline.

Nutrition researchers in Mali and in Norway have collaborated since 1996 with a non-governmental organisation (NGO) working in Bafoulabé in rural Western Mali. The aim of the collaboration is to assess and monitor the nutrition security situation in the area. This also includes data on food intake. The quantitative foodfrequency questionnaire (QFFQ) was chosen as the method for assessing food intake because it has the potential for use in collecting dietary intake data in larger population groups at relatively low cost.

This paper describes the validation of a 7-day quantitative food-frequency questionnaire, created for assessing the usual food intake in the prevailing season, to be used in studies on nutrition in Western Mali. Combined weighed and recalled diet record was chosen as the method of reference.

\section{Subjects and methods}

\section{Area and subjects}

The development of the quantitative food-frequency questionnaire and the validation study took place in a small village, Kersignané, in the Cercle of Bafoulabé. Bafoulabé is in the Kayes Region of Western Mali towards the border with Senegal. Bafoulabé is divided into several arondissements and Kersignané lies in the arondissement of Oussoubidiania, one of the arondissements where the NGO was active. The small village of Kersignané was chosen because it was accessible from the camp of the $\mathrm{NGO}$, only $3 \mathrm{~km}$ away, and it was one of the collaborating villages of the NGO, thus a basis for co-operation was expected.

The study protocol was approved by the Malian National Centre for Scientific and Technological Research (CNRST). Verbal consent was given from the survey participants after the study was fully explained to them.

A total of 269 persons lived in the village (census by the research group). Criteria for inclusion in the validation study were residence in the village, presence in the village the preceding week, and age 15 to 59 years. The 108 eligible persons in the village were invited to take part in the validation study. Of these, $31 \%$ either refused to participate (16 persons) or went away at the time of the study (17 persons). The validation study thus included 75 persons ( 48 women and 27 men) representing 18 different households (here defined as those who eat food prepared in the same pot).

\section{Study design}

Two men and two women from a nearby town were recruited as field workers, as were also two female nurses from the collaborating organisation. All the field workers had at least 12 years of education and spoke both French and the local language, Kassonké. The six field workers were thoroughly trained during three weeks by the study supervisor (IB, nutritionist). In this period, the field workers also participated in the development of the methods and the questionnaires, which gave them a good understanding of the aim and scope of the study and the precise meaning of the questions.

The validation study was conducted during eight weeks from October to December 1996, which corresponded to the season of sorghum and groundnut harvest in the area. In teams of two, the field workers spent three days in each household. The first day the study participants were interviewed about their food intake the preceding week by use of the quantitative food-frequency questionnaire. A questionnaire for background information (health, occupation, education and anthropometric measurements (height and weight)) was completed. The two following days the diet was recorded using weighed/recalled diet records (WRDR). The supervisor was present all the time, supervising the data collection and checking all the data on the spot.

\section{The quantitative food-frequency questionnaire (QFFQ)}

The quantitative food-frequency questionnaire was meant to cover all foods consumed, quantitatively and qualitatively, during the seven days preceding the interview. Through focus group interviews with four different groups, food items and dishes consumed in the village were identified. Information from these interviews and experience from other dietary surveys in $\mathrm{Mali}^{2,14}$ made the basis for a first version of the QFFQ. The questionnaire was tested three times in neighbouring villages to Kersignané in order to ensure completeness and functionality of the questionnaire.

The final version of the QFFQ contained a list of 69 food items (Appendix A). Open-ended questions on 'other foods consumed' were included at the end of the QFFQ.

When confirming an item, the number of times the food had been eaten during the past week (times per day and days per week) and the average amount of food eaten 
each time were registered in the questionnaire. Volume measures of different sizes were used for estimating amounts eaten of non-solid foods, groundnuts and beverages. The participants showed the amount consumed of a food, e.g. rice with sauce, using millet grains that were thereafter poured into the volume measure so that the amount could be read in decilitres. The sizes of single solid food items like fruit, vegetables and bread were estimated by drawing up the item on a blackboard, and indicating its two-dimensional measures.

In order to establish weight equivalencies for volumes for the different food items, four to eight samples of each item that had been reported consumed were measured and weighed using digital scales (Soehnle Digitals; $2 \mathrm{~g}$ precision for $0-2.5 \mathrm{~kg}$ and $5 \mathrm{~g}$ precision for $2.5-5 \mathrm{~kg}$ ). The average weight per decilitre, per $\mathrm{cm}$ or per square $\mathrm{cm}$, according to the type of food, was thereafter calculated, taking into account percentage of the food that was edible.

\section{The weighed/recalled diet records (WRDR)}

The combined weighed and recalled diet records were conducted for two subsequent days. The field workers registered both the ingredients of the dishes and the food intake for the three main meals: breakfast, lunch and supper. However, they left the households between these activities. After supper, recalls were done in order to register the foods that had been eaten between the main meals when the field workers were absent. The recalled amounts were estimated using the same methods as described for assessment of portions in the QFFQ.

The dishes were eaten from common plates using either hands or spoons (in the case of porridges). In order to measure the food intake, five handfuls or spoonfuls were weighed using digital scales (Soehnle Digitals; 0$5 \mathrm{~kg}$ ). The field worker counted the total number of hand-/spoonfuls eaten using a manual counter. A person's intake was thus calculated from the number of hand-/spoonfuls multiplied by the average weight of the five measured hand-/spoonfuls.

The ingredients of the dishes were weighed separately, using the same digital scales (Soehnle Digitals; 0-5 kg). The pans with the dish were weighed when ready to eat using digit scales with a maximum capacity of $120 \mathrm{~kg}$ and with $100 \mathrm{~g}$ precision (Soehnle Digitals).

\section{Nutrient calculations}

The food intake data were analysed using a software system developed at the Institute for Nutrition Research, University of Oslo, together with the Food Composition Table for Mali developed at the same institute ${ }^{19}$. Recipes for the dishes registered in the weighed/recalled diet records were calculated and amounts eaten of each dish were split into ingredients. Twenty-five different standard recipes were compiled based on the recipes from the WRDR (Appendix
B), and these were used in the calculation of intake from the food-frequency questionnaire.

\section{Use of basal metabolic rate (BMR) to evaluate the validity of the reference method}

The method described by Goldberg and co-workers ${ }^{20,21}$ for estimating under- or overreporting of energy intake was used for evaluating the intakes as measured in the weighed/recalled diet records. Estimates of BMR were calculated from standard formulas based on weight, age and $\operatorname{sex}^{22}$. The lower cut-off limit for the ratio between measured energy intake (EI) from the weighed/recalled diet records and BMR was calculated to be 1.00, using BMR estimates with 95\% confidence limits, a diet recording period of 2 days and a physical activity level (PAL) of 1.55. The upper cut-off limit, calculated with a PAL of 2.00, was found to be 3.11.

\section{Statistical methods}

Data from the dietary assessments were analysed using the Statistical Package for the Social Sciences (SPSS) ${ }^{23}$. Since most nutrient and food intakes were not normally distributed, non-parametric statistical methods were used. The sample median, and 25th and 75th percentiles of nutrient and food intakes were computed. Differences between the two methods were tested with Wilcoxon's signed rank test. The percentage of subjects with a difference in measured intakes between the two methods of less than $20 \%$ of the mean intake is presented as a measure of dispersion of the differences between paired observations $^{24}$. Bland and Altman plots ${ }^{25}$ were used to visualise this dispersion. Spearman rank correlation was used to assess the relative validity of the questionnaire. The agreement on category level between the questionnaire and the records was examined by classification of subjects into quartiles.

\section{Results}

Table 1 shows some characteristics of the study participants, where median age was 34 years for men and 33 years for women. Body mass index (BMI, $\mathrm{kg} \mathrm{m}^{-2}$ ) was around 19 for men and 20 for women. Fever/malaria was the most prevalent disease striking 33\% of the men and $48 \%$ of the women. French, the official language in Mali, was read and written by $18 \%$ of the men and $2 \%$ of the women. Agriculture was the main occupation, practised by more than 90\%. Most women (69\%) had at least two different occupations the preceding week, while this was the case for $33 \%$ of the men.

The median (25th percentile, 75 th percentile) ratio between energy intake as measured by the 2-day weighed/recalled diet records and estimated BMR was $2.00(1.58,2.59)$. Two persons had a ratio below 1.00 and six persons had a ratio above 3.11 . The ratio between energy intake as measured by the QFFQ and BMR was 
Table 1 Characteristics of the participants in the quantitative food-frequency questionnaire validation study, Mali 1996

\begin{tabular}{|c|c|c|c|c|}
\hline \multirow[b]{2}{*}{ Age (years) ${ }^{*}$} & \multicolumn{2}{|c|}{ Men $(n=27)$} & \multicolumn{2}{|c|}{ Women $(n=48)$} \\
\hline & 34 & $(21,44)$ & 33 & $(24,45)$ \\
\hline Weight $(\mathrm{kg})^{*}$ & 57.3 & $(52.3,60.2)$ & 52.1 & $(49.7,56.7)$ \\
\hline Height $(m)^{\star}$ & 1.71 & $(1.66,1.75)$ & 1.63 & $(1.59,1.68)$ \\
\hline BMI $\left(\mathrm{kg} \mathrm{m}^{-2}\right)^{\star}$ & 19.1 & $(18.4,20.3)$ & 19.9 & $(18.7,21.4)$ \\
\hline \multicolumn{5}{|c|}{ Illness the preceding week (\%) } \\
\hline Fever/malaria & 33 & & 48 & \\
\hline Diarrhoea & 7 & & 6 & \\
\hline Respiratory infection & 4 & & 23 & \\
\hline Read/write French (\%) & 18 & & 2 & \\
\hline \multicolumn{5}{|l|}{ Occupation (\%) } \\
\hline Agriculture & 96 & & 94 & \\
\hline Animal husbandry & 26 & & 12 & \\
\hline Housework & 0 & & 77 & \\
\hline Handicraft & 15 & & 33 & \\
\hline Other & 11 & & 2 & \\
\hline $\begin{array}{l}\text { At least two occupations } \\
\text { the preceding week (\%) }\end{array}$ & 33 & & 69 & \\
\hline
\end{tabular}

* Median and (25th, 75th percentiles).

slightly higher, with a median (25th percentile, 75th percentile) of $2.42(1.73,2.93)$.

Table 2 shows the intake of foods grouped into nine food groups, as measured by the quantitative foodfrequency questionnaire and by the weighed/recalled diet records. Intake of all food groups except meat/fish, sugar and tea/coffee were significantly higher in the questionnaire than in the diet records. The percentage of persons with a difference in measured intake as a percentage of mean intake of less than 20\% (Table 2) varied from $13 \%$ for fruit and vegetables to $42 \%$ for tea/coffee.

Intake of foods stratified by gender is also presented in Table 2. There was less difference in intake as measured with the two methods for men than for women. While men had significantly different estimated intakes of fruits/ vegetables and tea/coffee, women had significantly different intakes of cereals, meat/fish, green leaves, salt and sugar.

The Spearman rank correlation coefficient between pair-wise measurements by diet records and by the questionnaire (Table 3) ranged for the total sample from 0.09 for meat/fish (non-significant) to 0.58 for tea/coffee $(P<0.001)$. The median correlation was 0.37 . Stratified analysis by gender showed that men had a higher median correlation coefficient $(r=0.43)$ than did women $(r=$ $0.33)$.

Table 3 also shows the extent to which the questionnaire classified subjects into the same quartile of food intake calculated from the diet records and the extent to which it misclassified subjects into opposite quartiles. The proportion of subjects being classified into the same quartile ranged from $31 \%$ for green leaves to $47 \%$ for milk, with a median value of $33 \%$. Gross misclassification of subjects into opposite quartiles varied from 5\% to $9 \%$, with a median of $7 \%$.

Table 4 presents the intakes of energy and nutrients and the differences in intakes as measured by the foodfrequency questionnaire and the weighed/recalled diet records. The questionnaire had significantly higher intake estimates than the records of energy and all nutrients except for vitamin C. The median difference was 14\%, ranging from $8 \%$ for calcium to $26 \%$ for retinol and fat. The energy percentages from protein, fat and carbohydrates did not differ significantly between the two methods.

Persons with less than 20\% difference between the WRDR and the QFFQ ranged from 15\% for protein to 95\% for energy percentage from protein. There were large individual variations in the differences between the absolute values measured with the questionnaire and with the records (Figs 1 and 2). The difference in intake of energy plotted against the average intake of energy estimated by the two methods showed a certain increase in difference with increasing intakes (Fig. 1). This was more pronounced for intakes of protein (Fig. 2). Most of the nutrients showed plots similar to the plot of the energy intake.

The Spearman rank correlation coefficient between pair-wise measurements by the two methods (Table 5) ranged for the total sample from -0.11 for energy percentage from protein (non-significant) to 0.56 for vitamin C $(P<0.001)$. The median coefficient was 0.40 . When looking separately at men and women, the median correlation was higher for men $(r=0.42)$ than for women $(r=0.32)$. Adjustment for energy intake did not improve the correlations (data not shown).

Classification of individuals into the same quartiles according to their intake, as calculated from the WRDR and the QFFQ, ranged from 21\% for energy percentage from protein to $41 \%$ for niacin, the median percentage being 34\%. The percentage of subjects misclassified into extreme quartiles ranged from $0 \%$ to $12 \%($ median $=4 \%)$. 


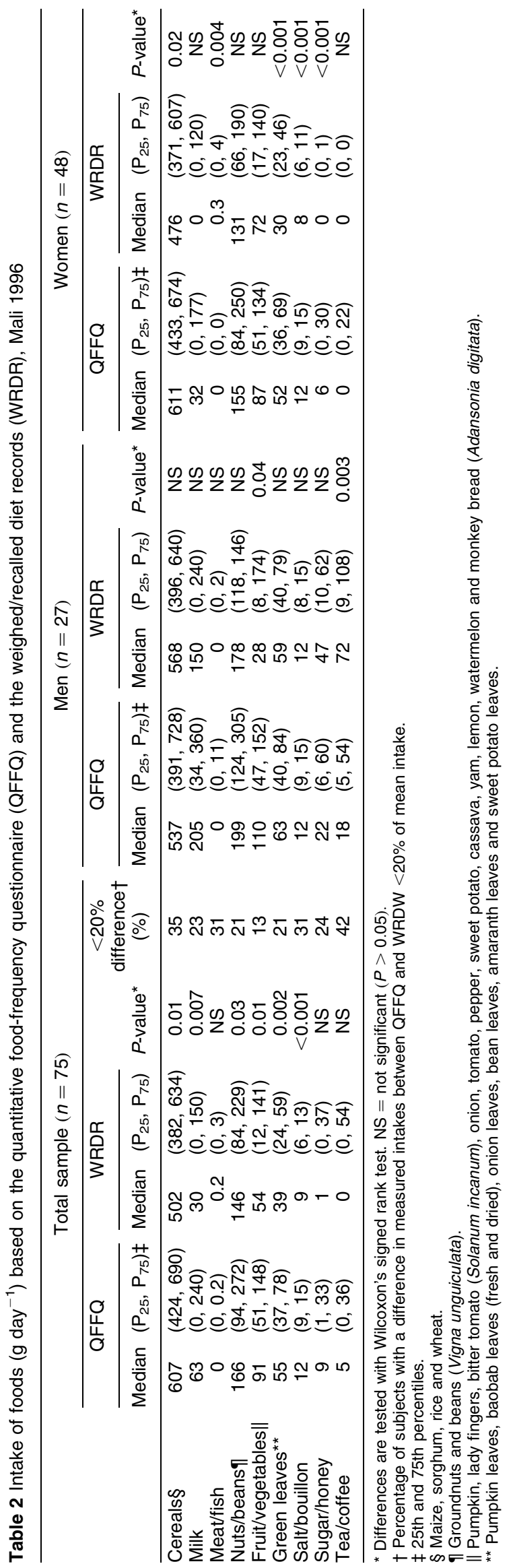

\section{Discussion}

In this study, the validity of a quantitative food-frequency questionnaire (QFFQ) for use in Western Mali was examined. The questionnaire was developed as a tool in the surveillance of the food and nutrition situation in the area. The food system in this area is characterised by self-subsistence farming supplemented with some gathering of wild foods, while little of the food is purchased ${ }^{26}$. This leads to relatively large seasonal variations in availability of foods, both in terms of quantity and quality. In order to reflect these seasonal variations this foodfrequency questionnaire covered only the week preceding the interview, which was meant to represent the habitual food consumption in the prevailing season. Thus, in order to describe the yearly food intake, evaluation studies should be repeated at all seasons.

In validation studies of dietary assessment methods, the reference method needs to be as accurate and precise as possible and the errors associated with the two methods should be independent ${ }^{27}$. The quantitative food-frequency questionnaire was therefore compared with results from weighed/recalled diet records during two subsequent days. The recording period of two days was chosen because of an assumed low intra-individual variation in this rural community; an assumption which is commonly held ${ }^{6,28}$. A longer registration period could better have reflected the true intake of the study sample; however, time, especially for the study participants, and economic resources were among the factors limiting the time frame.

The results show that use of only a limited number of food items was reported. The wild foods used included only the leaves and fruit from the baobab tree (Adansonia digitata). It might be that wild foods used as snacks inbetween meals have been underreported. Alcohol use was not reported, which might reflect the dominance of Muslims in the area. The field workers did not observe the use of alcohol in the village; however, underreporting cannot be completely ruled out. No fat was added in the food preparation, and the relatively high fat percentage is mainly due to the high intake of groundnuts, which constitutes one of the most important foods in the area.

The marginal situation the households lived in makes it unlikely that the presence of the field workers altered the habitual food intake. The field workers were instructed not to accept food in the households, and were also not allowed to buy anything in the village, both of which could lead to alterations.

The external validation of the reference method showed that two persons had a ratio of EI from the weighed/recalled records to estimated BMR below 1.00. Both persons, however, were suffering from illnesses that led to a low food intake, which was observed by the field workers. Six persons had a ratio above 3.11, which might indicate (1) overestimation of the food intake, (2) 
Table 3 Correlation (by Spearman) and classification of subjects (by quartiles of calculated food intake) when comparing food intake from the quantitative food-frequency questionnaire and the weighed/recalled diet records, Mali 1996

\begin{tabular}{|c|c|c|c|c|c|c|c|c|}
\hline \multirow[b]{3}{*}{ Cereals§ } & \multicolumn{6}{|c|}{ Spearman's $r^{*}$} & \multirow{2}{*}{$\begin{array}{l}\text { Correctly } \\
\text { classified (\%)† } \\
\quad(n=75)\end{array}$} & \multirow{2}{*}{$\begin{array}{c}\text { Grossly } \\
\text { misclassified (\%)‡ } \\
(n=75)\end{array}$} \\
\hline & \multicolumn{2}{|c|}{ Total sample $(n=75)$} & \multicolumn{2}{|c|}{ Men $(n=27)$} & \multicolumn{2}{|c|}{ Women $(n=48)$} & & \\
\hline & 0.31 & & 0.46 & & 0.25 & NS & 27 & 7 \\
\hline Milk & 0.46 & & 0.40 & & 0.34 & & 47 & 8 \\
\hline Meat/fish†† & 0.09 & NS & -0.04 & NS & 0.22 & NS & - & - \\
\hline Nuts/beans & 0.37 & & 0.36 & NS & 0.33 & & 33 & 5 \\
\hline Fruit/vegetables|| & 0.44 & & 0.39 & & 0.45 & & 44 & 5 \\
\hline Green leaves** & 0.15 & NS & 0.34 & NS & -0.07 & NS & 31 & 9 \\
\hline Salt/bouillon & 0.36 & & 0.16 & NS & 0.49 & & 27 & 5 \\
\hline Sugar/honey & 0.52 & & 0.59 & & 0.34 & & 39 & 7 \\
\hline Tea/coffee†† & 0.58 & & 0.80 & & 0.18 & NS & - & - \\
\hline
\end{tabular}

* If not otherwise indicated, correlation coefficients are significantly different from zero at $5 \%$ level $(P<0.05)$. NS $=$ not significant.

$\dagger$ Percentage of subjects classified into the same quartile of calculated food intake.

$\ddagger$ Percentage of subjects classified into the extreme quartiles of calculated food intake.

$\S$ Maize, sorghum, rice and wheat.

II Groundnuts and beans (Vigna unguiculata).

II Pumpkin, lady fingers, bitter tomato (Solanum incanum), onion, tomato, pepper, sweet potato, cassava, yam, lemon, watermelon and monkey bread (Adansonia digitata).

** Pumpkin leaves, baobab leaves (fresh and dried), onion leaves, bean leaves, amaranth leaves and sweet potato leaves.

t† Subjects not classified into quartiles since median intake with one of the methods is $0 \mathrm{~g} \mathrm{day}^{-1}$.

extremely high energy expenditure, (3) an increase in body weight (energy intake>total energy expenditure) or a combination of two or more of these factors. All of the six persons with EI/BMR above 3.11 were women. This study was done in the middle of the harvest season for sorghum and groundnuts, when the workload, especially for women, is very high ${ }^{29}$. This is also the time when food starts to be abundant after a period of scarcity ${ }^{29}$. It is possible that the very high energy intake observed for some individuals reflected a high energy expenditure at the same time as the individuals actually were increasing their weight after a period of scarcity. The six women with EI/BMR factor above 3.11 reported to have more activities the preceding week than the other women. They also had a lower BMI (19.0 vs. 20.0), however not statistically significant. It could be that some of the persons had overestimated their true intake as measured by the weighed/recalled records. However, the above mentioned factors might explain the very high EI/BMR ratios observed for the reference method.

Spearman rank correlation coefficients between intake as measured with the two methods for nutrients were comparable with some studies, ${ }^{9,30}$ while lower than others $^{12,16,31-33}$. The odd median correlation coefficient for energy percentage from protein of -0.11 may be due to a very low variation in that variable. The values are so close that even if the two methods do give similar results for most of the individuals when examining the data, the

Table 4 Daily intake of energy and nutrients based on measurements with the quantitative food-frequency questionnaire (QFFQ) and the weighed/recalled diet records (WRDR), Mali $1996(n=75)$

\begin{tabular}{|c|c|c|c|c|c|c|c|}
\hline & \multicolumn{2}{|c|}{ QFFQ } & \multicolumn{2}{|c|}{ WRDR } & \multirow[b]{2}{*}{$P$-value* } & \multirow{2}{*}{$\begin{array}{c}\text { QFFQ/WRDR } \times 100 \dagger \\
\text { (median) }\end{array}$} & \multirow{2}{*}{$\begin{array}{c}<20 \% \text { difference } \neq \\
(\%)\end{array}$} \\
\hline & Median & $\left(\mathrm{P}_{25}, \mathrm{P}_{75}\right) \S$ & Median & $\left(\mathrm{P}_{25}, \mathrm{P}_{75}\right) \S$ & & & \\
\hline Energy (MJ) & 14.2 & $(9.9,18.2)$ & 11.2 & $(8.9,15.4)$ & 0.01 & 115 & 31 \\
\hline Protein (g) & 106 & $(70,129)$ & 81 & $(61,111)$ & $<0.001$ & 119 & 15 \\
\hline Fat $(\mathrm{g})$ & 111 & $(69$ 172) & 91 & $(63,132)$ & 0.004 & 126 & 23 \\
\hline Carbohydrate (g) & 518 & $(368,610)$ & 425 & $(322,561)$ & 0.004 & 112 & 36 \\
\hline Retinol eq. $(\mu \mathrm{g})$ & 462 & $(302,645)$ & 317 & $(172,536)$ & $<0.001$ & 126 & 28 \\
\hline Thiamine (mg) & 2.8 & $(1.9,3.5)$ & 2.2 & $(1.7,3.0)$ & 0.001 & 117 & 32 \\
\hline Riboflavin (mg) & 2.4 & $(1.5,3.3)$ & 1.8 & $(1.3,2.5)$ & 0.001 & 122 & 29 \\
\hline Niacin (mg) & 25.9 & $(17.8,31.8)$ & 21.3 & $(16.3,29.2)$ & 0.01 & 115 & 40 \\
\hline Vitamin C (mg) & 51 & $(35,73)$ & 45 & $(24,75)$ & NS & 112 & 27 \\
\hline Calcium (mg) & 746 & $(464,1049)$ & 591 & $(399,852)$ & 0.017 & 108 & 25 \\
\hline Iron (mg) & 61 & $(37,79)$ & 48 & $(37,65)$ & 0.004 & 117 & 31 \\
\hline \multicolumn{8}{|l|}{$\%$ energy } \\
\hline Protein & 11.6 & $(11.2,12.1)$ & 11.3 & $(11.1,11.7)$ & NS & 101 & 95 \\
\hline Fat & 28.6 & $(23.6,35.5)$ & 28.6 & $(22.3,34.4)$ & NS & 102 & 44 \\
\hline Carbohydrate & 59.3 & $(52.9,64.6)$ & 59.8 & $(54.2,65.8)$ & NS & 98 & 75 \\
\hline
\end{tabular}

* Differences are tested with Wilcoxon's signed rank test. NS = not significant $(P>0.05)$.

$\dagger$ Intake measured by the quantitative food-frequency questionnaire as percentage of that measured by the weighed/recalled diet records.

¥ Percentage of subjects with a difference in measured intakes between QFFQ and WRDW $<20 \%$ of mean intake.

$\S 25$ th and 75 th percentiles. 


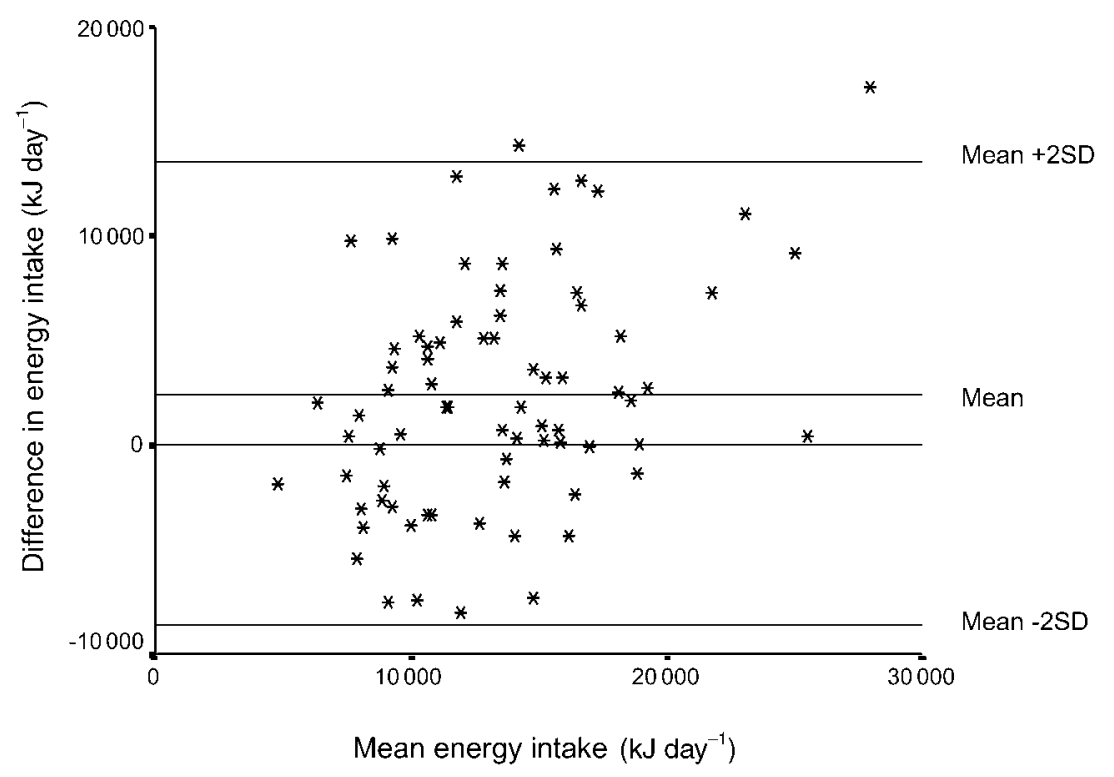

Fig. 1 The difference in energy intake measured with the questionnaire and the diet record, plotted against the mean of the energy intake measured with the two methods $(n=75) . \mathrm{SD}=$ standard deviation

ranking has become obscured, leading to a low Spearman rank correlation coefficient.

Also, correlation coefficients for food intake were similar to ${ }^{33}$ or lower than ${ }^{16,31,34,35}$ what has been found in other studies. The correlation was particularly low (non-significant) for green leaves and for meat/fish. The low correlation for meat/fish might be due to the fact that meat/fish was rarely eaten. Intake of meat/fish (more than $1 \mathrm{~g} \mathrm{day}^{-1}$ ) was recorded for only $32 \%$ of the study participants in the 2-day diet records and 23\% in the quantitative food-frequency questionnaire. Thus, the relatively short registration period of two days for the reference method might not have captured the intake of rarely eaten foods, as is also discussed by Willett ${ }^{28}$.

In epidemiological studies, correct classification of individuals is essential ${ }^{36}$. We evaluated the extent to which intake from the quantitative food-frequency questionnaire assigned the subjects into the same quartile of the distribution as defined by the diet records. The foodfrequency questionnaire had a satisfactory ability to rank subjects for intake of most groups of foods and nutrients. However, the ability to correctly classify subjects according to intake of cereals and salt/bouillon was not adequate. The ability to correctly classify subjects

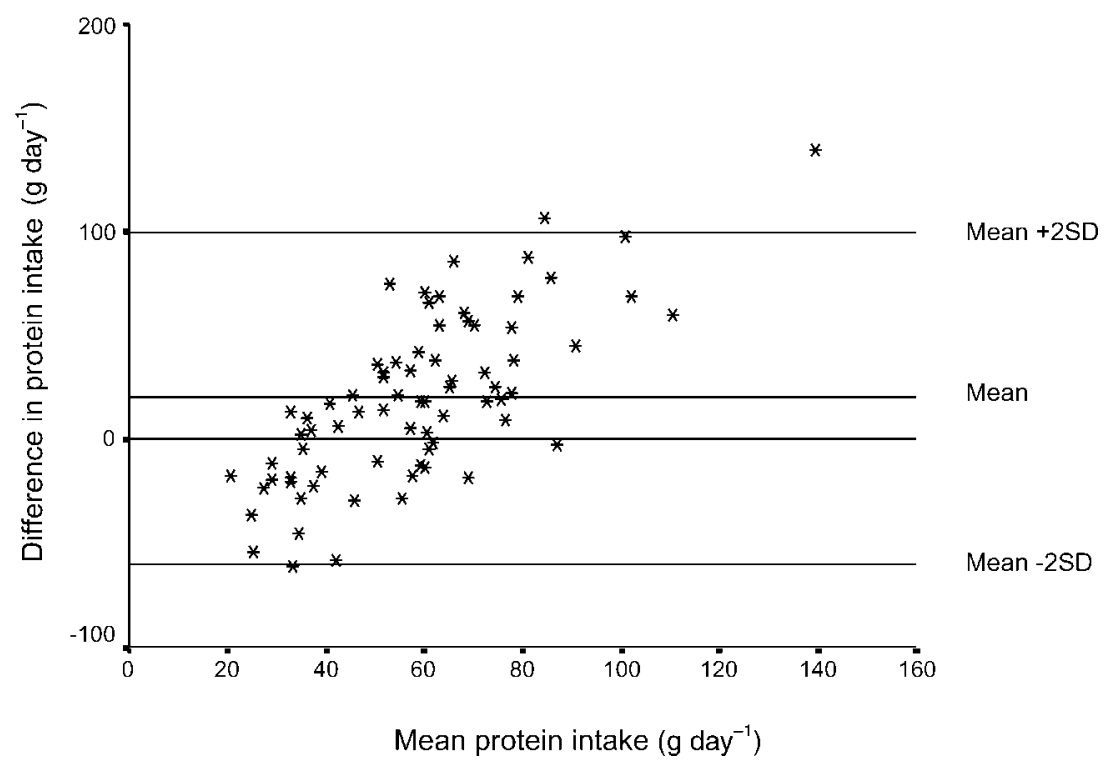

Fig. 2 The difference in protein intake measured with the questionnaire and the diet record, plotted against the mean of the protein intake measured with the two methods $(n=75)$. SD $=$ standard deviation 
Table 5 Correlation (by Spearman) and classification of subjects (by quartiles of calculated nutrient intake) when comparing nutrient intake from the quantitative food-frequency questionnaire and the weighed/recalled diet records, Mali 1996

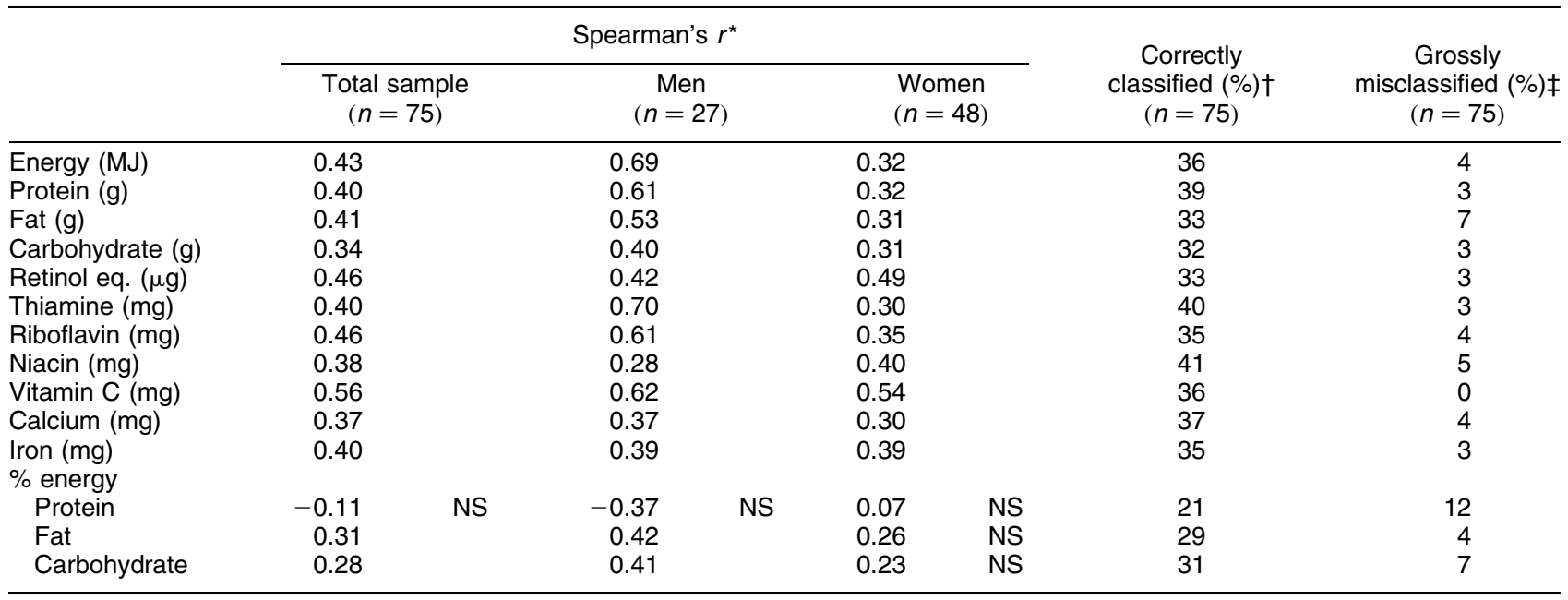

* If not otherwise indicated, correlation coefficients are significantly different from zero at $5 \%$ level $(P<0.05)$. NS $=$ not significant.

$\dagger$ Percentage of subjects classified into the same quartile of calculated nutrient intake.

$\ddagger$ Percentage of subjects classified into the extreme quartile of calculated nutrient intake.

according to food intake was lower than reported by both Bonifacj and co-workers ${ }^{32}$ and Elmståhl and co-workers $^{34}$. The classification in terms of nutrients was overall better than for foods. This reflects the lower day-to-day variation in intake of many nutrients compared with that of many foods ${ }^{37}$.

The quantitative food-frequency questionnaire gave higher intakes than weighed/recalled records, which may be caused by overestimation. Underestimation by the weighed records does not appear to be a problem, in view of the high EI/BMR factors. The higher intakes were quite uniform for most of the foods and nutrients. It seems unlikely that an overestimation was due to a wish for showing high social status ${ }^{6}$, since one of the high-status foods, meat, was not overreported. Men had in general a better agreement between the two methods than women, but had to a higher extent overestimated some foods that are often eaten in-between meals (tea/coffee and fruit/ vegetables). The women, on the other hand, seemed to have overestimated the food groups that are in general eaten in the main meals (cereals, green leaves and salt/ bouillon). Overestimation by food-frequency questionnaire is a common problem ${ }^{11,12,33,34,38}$, and has consequences when the intention is to assess actual and not relative intake of foods and nutrients ${ }^{37}$.

However, since the quantitative food-frequency questionnaire is able to rank subjects adequately according to intake for most foods and nutrients, it represents a useful tool in the surveillance of food intake in the population, both in identifying vulnerable groups and for tracking changes in food intake over time. But the difference between men and women in overestimating food intake needs to be taken into account when using the method.

Because one is also interested in actual food intake in the nutritional surveillance of populations, efforts should be made to identify the sources of error and to improve the questionnaire.

\section{References}

1 FAO/WHO. Nutrition and Development - A Global Assessment. International Conference on Nutrition. Rome: Food and Agriculture Organization of the United Nations/World Health Organization, 1992.

2 Hatløy A, Torheim LE, Oshaug A. Food variety - a good indicator of nutritional adequacy of the diet? A case study from an urban area in Mali, West Africa. Eur. J. Clin. Nutr. 1998; 52: 891-8.

3 Dop MC, Milan C, Milan C, N'Diaye AM. Use of the multipleday weighed record for Senegalese children during the weaning period: a case of the 'instrument effect'. Am.J. Clin. Nutr. 1994; 59: 266S-8S.

4 Ferguson EL, Gibson RS, Opare-Obisaw C, Osei-Opare F, Lamba C, Ounpuu S. Seasonal food consumption patterns and dietary diversity of rural preschool Ghanaian and Malawian children. Ecol. Food Nutr. 1993; 29: 219-34.

5 Ferguson EL, Gibson RS, Opare-Obisaw C. The relative validity of the repeated $24 \mathrm{~h}$ recall for estimating energy and selected nutrient intakes of rural Ghanaian children. Eur. J. Clin. Nutr. 1994; 48: 241-52.

6 Kigutha HN. Assessment of dietary intake in rural communities in Africa: experiences in Kenya. Am. J. Clin. Nutr. 1997; 65: 1168S-72S.

7 FAO/WHO. World Declaration and Plan of Action for Nutrition. International Conference on Nutrition. Rome: Food and Agriculture Organization of the United Nations/ World Health Organization, 1992.

$8 \mathrm{FAO} / \mathrm{WHO}$. Preparation and Use of Food-based Dietary Guidelines. WHO Technical Report Series. Geneva: World Health Organization, 1998.

9 Willett WC, Sampson L, Stampfer MJ, Rosner B, Bain C, Witschi J, et al. Reproducibility and validity of a semiquantitative food-frequency questionnaire. Am. J. Epidemiol. 1985; 122: 51-65. 
10 Kushi LH. Gaps in epidemiologic research methods: design considerations for studies that use food-frequency questionnaires. Am. J. Clin. Nutr. 1994; 59: 180S-4S.

11 Hebert JR, Gupta PC, Bhonsle RB, Sinor PN, Mehta H, Mehta FS. Development and testing of a quantitative food frequency questionnaire for use in Gujarat, India. Public Health Nutr. 1999; 2: 39-50.

12 Hebert JR, Gupta PC, Bhonsle RB, Murti PR, Mehta H, Verghese F, et al. Development and testing of a quantitative food frequency questionnaire for use in Kerela, India. Public Health Nutr. 1998; 1: 123-30.

13 Sharma S, Cade J, Jackson M, Mbanya JC, Chungong S, Forrester T, et al. Development of food frequency questionnaires in three population samples of African origin from Cameroon, Jamaica and Caribbean migrants to the UK. Eur. J. Clin. Nutr. 1996; 50: 479-86.

14 Hatløy A, Hallund J, Diarra MM, Oshaug O. Food variety, socioeconomic status and nutritional status in urban and rural areas in Koutiala (Mali). Public Health Nutr. 2000; 3 $57-65$.

15 Cassidy CM. Walk a mile in my shoes: culturally sensitive food-habit research. Am. J. Clin. Nutr. 1994; 59: 190S-7S.

16 Nes M, Andersen LF, Solvoll K, Sandstad B, Hustvedt BE, Løvø A, et al. Accuracy of a quantitative food frequency questionnaire applied in elderly Norwegian women. Eur.J. Clin. Nutr. 1992; 46: 809-21.

17 Bingham SA, Gill C, Welch A, Day K, Cassidy A, Khaw KT, et al. Comparison of dietary assessment methods in nutritional epidemiology: weighed records v. $24 \mathrm{~h}$ recalls, food-frequency questionnaires and estimated-diet records. Br. J. Nutr. 1994; 72: 619-43.

18 Andersen LF. Evaluation of food frequency questionnaires used among different groups of the Norwegian population. Dissertation, Institute for Nutrition Research, University of Oslo, 1998

19 Nordeide MB. Table de Composition d'Aliments du Mali. Annex No. 9. Rapport d'Etape Sécurité Alimentaire/Femme. Projet de Recherche SSE. Environnement et Développement au Mali. Oslo: CNRST/Université d'Oslo, 1997.

20 Goldberg GR, Black AE, Jebb SA, Cole TJ, Murgatroyd PR, Coward WA, et al. Critical evaluation of energy intake data using fundamental principles of energy physiology: 1 . Derivation of cut-off limits to identify under-recording. Eur. J. Clin. Nutr. 1991; 45: 569-81.

21 Goldberg GR, Black AE. Assessment of the validity of reported energy intakes - review and recent developments. Scand. J. Nutr. 1998; 42: 6-9.

22 FAO/WHO/UNU. Energy and Protein Requirements. Technical Report Series 724. Geneva: World Health Organization, 1985.

23 SPSS, Inc. SPSS 8.0 for Windows. Chicago, IL: SPSS, Inc., 1997.

24 Burema J, van Staveren WA, Feunekes GIJ. Guidelines for reports on validation studies. Eur. J. Clin. Nutr. 1995; 49: 932-3.

25 Bland JM, Altman DG. Statistical methods for assessing agreement between two methods of clinical measurement. Lancet 1986; i: 307-10.

26 Oshaug A, Diarra M, Torheim LE, Diallo F, Diakité M, Sissoko F, et al. Etude qualitative des besoins de la population à Bafoulabé. Programme de collaboration PIDEB/INRSP/Université de Oslo, Oslo, 1997.

27 Kaaks R, Riboli E, van Staveren W. Calibration of dietary intake measurements in prospective cohort studies. Am. J. Epidemiol. 1995; 142: 548-56.

28 Willett WC. Nutritional Epidemiology. Oxford: Oxford University Press, 1990.

29 Adams AM. Seasonal variations in energy balance among agriculturalists in central Mali: compromise or adaptation? Eur. J. Clin. Nutr. 1995; 49: 809-23.

30 Pietinen P, Hartman AM, Haapa E, Räsänen L, Haapakoski J, Palmgren $\mathrm{J}$, et al. Reproducibility and validity of dietary assessment instruments. II. A qualitative food frequency questionnaire. Am. J. Epidemiol. 1988; 128: 667-76.

31 Goldbohm RA, van den Brandt PA, Brants HA, van't Veer P, $\mathrm{Al}$ M, Sturmans F, et al. Validation of a dietary questionnaire used in a large-scale prospective cohort study on diet and cancer. Eur. J. Clin. Nutr. 1994; 48: 253-65.

32 Bonifacj C, Gerber M, Scali J, Daures JP. Comparison of dietary assessment methods in a Southern French population: use of weighed records, estimated-diet records and a food-frequency questionnaire. Eur. J. Clin. Nutr. 1997; 51: 217-31.

33 Andersen LF, Nes M, Lillegaard IT, Sandstad B, Biørneboe GEA, Drevon CA. Evaluation of a quantitative food frequency questionnaire used in a group of Norwegian adolescents. Eur. J. Clin. Nutr. 1995; 49: 543-54.

34 Elmståhl S, Riboli E, Lindgärde F, Gullberg B, Saracci R. The Malmö food study: the relative validity of a modified diet history method and an extensive food frequency questionnaire for measuring food intake. Eur. J. Clin. Nutr. 1996; 50: $143-51$.

35 Salvini S, Hunter DJ, Sampson L, Stampfer MJ, Colditz GA, Rosner B, et al. Food-based validation of dietary questionnaire: the effects of week-to-week variation in food consumption. Int. J. Epidemiol. 1989; 18: 858-66.

36 Beaton GH. Approaches to analysis of dietary data: relationship between planned analysis and choice of methodology. Am. J. Clin. Nutr. 1994; 59: 253S-61S.

37 Nelson $\mathrm{M}$. The validity of dietary assessment. In: Margetts MB, Nelson M, eds. Design Concepts in Nutritional Epidemiology, 2nd ed. Oxford: Oxford University Press, 1997; 241-72.

38 Bingham SA, Day NE. Using biochemical markers to assess the validity of prospective dietary assessment methods and the effect of energy adjustment. Am.J. Clin. Nutr. 1997; 65: $11305-7 S$. 
Appendix A: Food items included in the quantitative food-frequency questionnaire for use among adults in Western Mali

\begin{tabular}{|c|c|c|c|}
\hline \multicolumn{3}{|c|}{ Local name (Kassonké) } & Description/main ingredients \\
\hline \multicolumn{4}{|c|}{ Staple dishes } \\
\hline 1.1 & Tuwo & & Lunch/dinner porridge made from flour \\
\hline 1.2 & Futo & & Steamed flour ('couscous') \\
\hline 1.3 & Sassaro & & Breakfast porridge \\
\hline 1.4 & Mono & & Breakfast porridge \\
\hline 1.5 & Gnelinkino & & Lunch/dinner porridge made from crunched cereals \\
\hline 1.6 & Dego & & As tuwo, but with milk and/or sugar \\
\hline 1.7 & Kagnikagno & & As futo, but made with groundnut paste and other ingredients \\
\hline 1.8 & Futiyo & & Dried futo with groundnut paste and other ingredients \\
\hline 1.9 & Maalukino & & Steamed rice \\
\hline 1.10 & Makoroni & & Macaroni with tomato sauce \\
\hline 1.11 & Jenaranxo & & Boiled pumpkin with groundnut paste \\
\hline 1.12 & Sosowulingo & & Bean stew \\
\hline 1.13 & Jeyeleningno & & Boiled pumpkin \\
\hline 1.14 & Juka & & Crushed cereals with groundnut paste and other ingredients \\
\hline 1.15 & Foyo & & Steamed fonio \\
\hline 1.16 & Sola & & Flour and lady fingers \\
\hline 1.17 & Laro & & Crushed cereals with butter \\
\hline 1.18 & Xunduba & & Boiled sweet potato \\
\hline 1.19 & Bantara & & Boiled manioc \\
\hline 1.20 & Gnelinyeleningno & & Crushed cereals prepared with green leaves \\
\hline \multicolumn{4}{|r|}{ 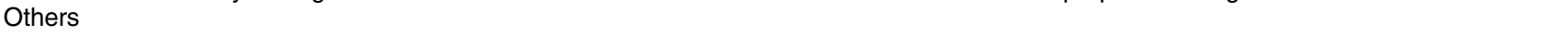 } \\
\hline \multicolumn{4}{|c|}{ Sauces } \\
\hline 2.1 & Tigadego & & Groundnut paste \\
\hline 2.2 & Sinbarajiyo & & Onion \\
\hline 2.3 & Xulangno & & Groundnut paste and onion \\
\hline 2.4 & Gnugusasaro & & Bean leaves \\
\hline 2.5 & Matura & & Pumpkin and pumpkin leaves \\
\hline 2.6 & Tigantangno & & Green leaves \\
\hline 2.7 & Xanjakerengno & & Fresh okra \\
\hline 2.8 & Xanjakunna & & Dried okra \\
\hline 2.9 & Sitana & & Baobab leaves \\
\hline 2.10 & Naxulunxulungno & & Powder of baobab leaves \\
\hline 2.11 & Sobona & & Sobo leaves \\
\hline \multicolumn{4}{|c|}{ Others } \\
\hline \multicolumn{4}{|c|}{ Other food items } \\
\hline 3.1 & Manioc & 3.21 & Galett \\
\hline 3.2 & Groundnuts & 3.22 & Mango \\
\hline 3.3 & Goat's milk & 3.23 & Lettuce \\
\hline 3.4 & Sheep's milk & 3.24 & Papaya \\
\hline 3.5 & Cow's milk & 3.25 & Tomato \\
\hline 3.6 & Dried milk & 3.26 & Bonbons \\
\hline 3.7 & Concentrated milk & 3.27 & Honey \\
\hline 3.8 & Bread & 3.28 & 'Sugar cane' from sorghum \\
\hline 3.9 & Wild yam & 3.29 & Coffee (with sugar and milk) \\
\hline 3.10 & Carrots & 3.30 & Green tea (with sugar) \\
\hline 3.11 & Cauliflower & 3.31 & Lipton thee (with sugar) \\
\hline 3.12 & Lemon & 3.32 & Traditional alcoholic drink \\
\hline 3.13 & Cucumber & 3.33 & Soft drink \\
\hline 3.14 & Cabbage & 3.34 & Dugutu (wild fruit; Cordyla pinata) \\
\hline 3.15 & Koronifin (wild fruit; Vitex doniana) & 3.35 & Boiled maize \\
\hline 3.16 & Saba (wild fruit) & 3.36 & Grilled maize \\
\hline 3.17 & Monkey bread & 3.37 & Seno (wild fruit; Ximenia americana) \\
\hline 3.18 & Jujub (wild fruit; Zizyphus mauritania) & 3.38 & Kunje (wild fruit; Hexalatus honopetalis) \\
\hline 3.19 & Fruit of African fan palm & Others & \\
\hline 3.20 & Grilled meat & & \\
\hline
\end{tabular}


Appendix B: Description of standard recipes used for calculating intake from the quantitative food-frequency questionnaire

\begin{tabular}{|c|c|c|c|}
\hline Number* & & Ingredients $†$ & $\begin{array}{l}\text { Number of } \\
\text { recipes } \neq\end{array}$ \\
\hline \multicolumn{4}{|l|}{ Staple foods } \\
\hline 1.2 & Futo/maize & Maize (flour), water, baobab leaves (dried) & 17 \\
\hline 1.2 & Futo/sorghum & Sorghum (flour), water, baobab leaves (dried) & 24 \\
\hline 3.5 & Milk with futo/sorghum & Sorghum (flour), water, baobab leaves (dried), milk & 1 \\
\hline 3.5 & Milk with futo/maize & Maize (flour), water, baobab leaves (dried), milk & 1 \\
\hline 1.3 & Sassaro/maize & Maize (crushed), water & 14 \\
\hline 1.3 & Sassaro/sorghum & Sorghum (crushed), water & 6 \\
\hline 1.3 & Sassaro/rice & Rice, water & 2 \\
\hline 1.4 & Mono/maize & Maize (flour), water, salt & 5 \\
\hline 1.4 & Mono/sorhum & Sorghum (flour), water, salt & 17 \\
\hline 1.4 & Mono/millet & Millet (flour), water, salt & 1 \\
\hline 1.5 & Gnelinkino/maize & Maize (crushed), water & 12 \\
\hline 1.5 & Gnelinkino/sorghum & Sorghum (crushed), water & 13 \\
\hline 1.9 & Maalukino & Rice, water & 1 \\
\hline 1.12 & Sosowulingo & Water, groundnut paste, beans, salt & 1 \\
\hline 1.14 & Juka & Sorghum (crushed), water, groundnut paste & 1 \\
\hline 1.17 & Laro & $\begin{array}{l}\text { Sorghum (crushed), water, groundnut paste, } \\
\text { oinon leaves, salt, bouillon cube, pepper }\end{array}$ & 1 \\
\hline 1.20 & Gnelenyeningno/maize & Maize (crushed), water, baobab leaves (dried) & 3 \\
\hline 1.20 & Gnelenyeningno/sorghum & Sorghum (crushed), water, baobab leaves (dried) & 5 \\
\hline \multicolumn{4}{|l|}{ Sauces } \\
\hline 2.1 & Tigadego & $\begin{array}{l}\text { Water, groundnut paste, onion leaves, beans, } \\
\text { tomatoes, bouillon cube, salt, pepper }\end{array}$ & 25 \\
\hline 2.3 & Xulangno & $\begin{array}{l}\text { Water, groundnut paste, onion leaves, beans, } \\
\text { tomatoes, dried fish, salt }\end{array}$ & 7 \\
\hline 2.4 & Gnugusasaro & $\begin{array}{l}\text { Water, groundnut paste, onion leaves, green leaves, } \\
\text { salt, bouillon cube }\end{array}$ & 12 \\
\hline 2.5 & Matura & $\begin{array}{l}\text { Water, groundnut paste, onion leaves, pumpkin, } \\
\text { pumpkin leaves, salt, bouillon cube, pepper }\end{array}$ & 7 \\
\hline 2.7 & Xanjakerengno & $\begin{array}{l}\text { Water, okra, groundnut paste, onion leaves, } \\
\text { pumpkin leaves, tomatoes, salt, pepper, bouillon cube }\end{array}$ & 16 \\
\hline 2.8 & Xanjakunna & $\begin{array}{l}\text { Water, okra (dried), groundnut paste, onion leaves, } \\
\text { bean leaves, salt, pepper, bouillon cube }\end{array}$ & 7 \\
\hline
\end{tabular}

* Corresponds to the number in Appendix A.

$\dagger$ Amount of each ingredient is available but is not shown here.

¥ Number of recipes each standard recipe is based on. 